\title{
Association and Path Coefficient Analysis of Various Component Traits with Seed Yield Per Plant for Quantitative Traits in Advance Generation (F5) of Cross Between Green Seeded Desi (GKB-10) and White Kabuli (MNK-1) Chickpea Genotypes (Cicer arietinum L.)
}

\author{
Honnappa $^{1 *}$, D.M. Mannur ${ }^{2}$ and S. Muniswamy ${ }^{3}$ \\ ${ }^{1}$ Department of Genetics and Plant Breeding, UAS, Raichur-584104, Karnataka, India \\ ${ }^{2}$ AICRP Chickpea, ARS Kalaburgi, Karnataka, India \\ ${ }^{3}$ Department of Genetics and Plant Breeding, A. C. Kalaburgi, UAS Raichur, \\ Karnataka, India \\ *Corresponding author
}

\section{A B S T R A C T}

Keywords

Seed yield per plant, Indirect selection, Association and path coefficient analysis.

Article Info

Accepted: 06 December 2017 Available Online: 10 January 2018
A study on association and path coefficient analysis for seed yield per plant and its component traits in Advance Generation (F5) of Cross Between Green Seeded Desi (GKB-10) and White Kabuli (MNK-1) Chickpea Genotypes is carried out during 2016-2017 at ARS Kalaburagi, University of agricultural science Raichur, Karnataka, India. The experiment was carried out in augmented design. Among the 14 quantitative characters studied, biological yield, number of secondary branches per plant, total number of pods per plant, harvest index, plant height and basal height revealed significant and positive association with seed yield per plant. Six out of 14 characters had positive and direct effect on seed yield per plant at phenotypic level.

\section{Introduction}

Improvement of yield, the most important target in many crops can be achieved by indirect selection through other easily observable characters. But this needs a good understanding of the association of different traits with seed yield and association among themselves. The association, direct and indirect effects of different traits vary with breeding material and environment. Therefore the information on the association of various traits among themselves and with seed yield provides useful information for successful breeding programme. In plant breeding correlation studies pave the way to know the association prevailing between highly heritable characters with most economic characters and give better understanding of the contribution of each trait in building up the genetic makeup of the crop. Practically all the metric traits in plants are interdependent and interrelated, if selection is practiced considering only one trait, naturally the others 
also would be affected. In such cases the knowledge of association between characters is quite helpful to plant breeders to formulate their selection strategy based on two or more traits simultaneously. Since, seed yield is complex quantitative characters; direct selection may not be a reliable approach as these traits are influenced by environmental factors. Therefore, it becomes essential to identify the component characters through which yield improvement could be obtained. Though correlation gives information about the contributing component of these complex characters, it does not provide an exact picture of relative importance of direct and indirect contribution of the component characters. Path coefficient analysis is an important tool for partitioning the correlation coefficient into direct and indirect effects. Thus, correlation in combination with path analysis would give better insight into the cause and effect relationship between different character pairs.

Selection for a specific character is known to result in correlated response in certain other characters, generally plant breeders practice selection for one or two attributes at a time. Then it becomes important to know the effect of selection on other characters. Study of nature of association of component traits with seed yield and among themselves in $F_{5}$ populations and study of the contribution of components towards seed yield through path analysis provides an opportunity for indirect selection of these component traits to improve complex trait like yield.

\section{Materials and Methods}

The experimental material comprised 90 green seeded chickpea genotypes developed by $\mathrm{F}_{5}$ (advance generation) of cross Between Green Seeded Desi (GKB-10) and White Kabuli (MNK-1) Chickpea genotypes along with 4 standard checks viz., MNK-1, GKB-10, KAK2 and JG-11 obtained from ARS Kalaburagi, were planted in augmented block design, during 2016-17.

The genotypes were planted in six blocks which was consisted of two rows of each genotype with a plant-to-plant and row-to-row distance of 10 and $30 \mathrm{~cm}$, respectively. Recommended cultural practices were carried out to maintain healthy crop growth. Number of days to flowering was recorded at the time when at least $50 \%$ plants showed the appearance of first flower. At maturity, data were recorded for yield and its various components including, number of primary branches per plant, number of secondary branches per plant, 100-seed weight and seed yield per plant. The data was subjected to statistical analysis by statistical software WINDOSTAT package, 8.1version. Pearson correlation coefficient is a statistical measure which is used to find out the degree and direction of relationship between two or more variables. It is represented by r. Genotypic and phenotypic correlation coefficients were calculated according to the method followed by Singh and Chaudhary (1979).

\section{Results and Discussion}

\section{Correlation analysis between yield components for green chickpea genotypes}

Associations between 14 important quantitative characters in the advance population of GKB-10 $\times$ MNK-1 with seed yield per plant are presented in (Table 1). Among the 14 characters studied, biological yield, number of secondary branches per plant, total number of pods per plant, harvest index, plant height and basal height revealed significant and positive association with seed yield per plant. While the overall association of all the characters contributed to seed yield through the influence of following independent traits. 
Further inter correlation among the important traits, the seed yield per plant positive significantly correlated with width of leaf let size (0.23), length of leaf let size (0.24), plant height (0.40),number of secondary branches per plant (0.51), number of pods per plant (0.51), biological yield per plant (0.76) and harvest index (0.46), these findings are supported by earlier findings of (Bakhsh et al., 2006; Durga et al., 2007; Dhameliya et al., 2008 and Sanjeev kumar, 2016). The leaf let size had significantly positive correlation with width of leaf let size (0.85), plant height (0.34), basal height (0.42), biological yield per plant (0.27) and test weight (0.49). Whereas this trait is negatively correlated with number of seeds per pod, further width of leaf let size has significantly positive correlation with plant height (0.34), basal height (0.35), biological yield (0.30) and test weight (0.40) and negatively correlated with number of seeds per pod.

Further plant height shows the significant positive correlation with basal height (0.86), number of secondary branches per plant (0.35), biological yield (0.38) and test weight (0.34). Number of secondary branches per plant is contributing to seed yield per plant by positive correlation with number of pods per plant (0.35) and biological yield per plant (0.60). The important trait pods per plant contributing to seed yield per plant by positive correlation with number of seeds per pod (0.29), biological yield per plant (0.45) and negatively correlated with test weight $(-0.33)$, these findings are supported by earlier findings of Babbar and Patel (2005), Akanksha et al., (2016), Anita et al., (2015), Mishra and Babbar (2014).

\section{Path coefficient analysis}

Direct and indirect effect for seed yield among 14 characters was estimated to know the nature of path coefficient existing among them. The results are presented in (Table 2) and phenotypic path diagram is presented in (Fig. 1).

Fig.1 Path diagram indicating direct and indirect effect of quantitative characters on seed yield at phenotypic level

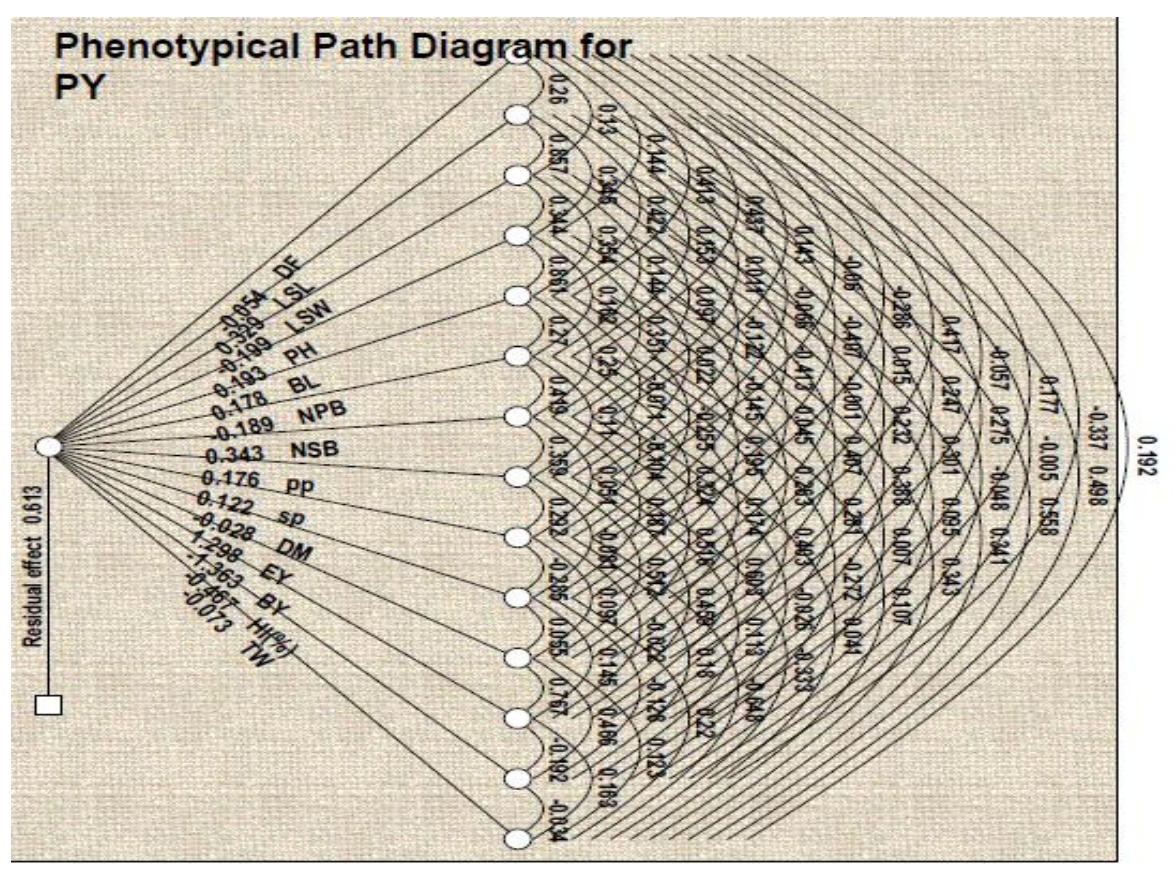


Table.1 Association between 14 quantitative traits of green chickpea genotypes at phenotypic level

\begin{tabular}{|c|c|c|c|c|c|c|c|c|c|c|c|c|c|c|c|}
\hline Traits & DE & DF & LLS & WLS & PH & $\mathbf{B H}$ & NPB & NSB & $\mathbf{P} / \mathbf{P}$ & $\mathbf{S} / \mathbf{P}$ & DM & BY & HI (\%) & TW & SYP \\
\hline DF & -0.0535 & 1 & $0.26^{*}$ & 0.13 & 0.14 & $0.41 * *$ & $0.43 * *$ & 0.14 & -0.06 & $-0.28 * *$ & $0.41 * *$ & 0.17 & $-0.33 * *$ & 0.19 & -0.05 \\
\hline LSL & 0.329 & & 1 & $0.85^{* *}$ & $0.34 * *$ & $0.42 * *$ & 0.15 & 0.01 & -0.06 & $-0.40 * *$ & 0.01 & $0.27 * *$ & -0.005 & $0.49 * *$ & $0.24 *$ \\
\hline LSW & -0.1994 & & & 1 & $0.34 * *$ & $0.35 * *$ & 0.14 & 0.09 & -0.12 & $-0.41 * *$ & -0.001 & $0.30 * *$ & -0.04 & $0.55^{* *}$ & $0.23 *$ \\
\hline$\overline{\mathbf{P H}}$ & 0.1927 & & & & 1 & $0.86 * *$ & 0.16 & $0.35 * *$ & 0.02 & -0.14 & 0.04 & $0.38 * *$ & 0.09 & $0.34 * *$ & $0.40 * *$ \\
\hline $\mathbf{B H}$ & 0.1781 & & & & & 1 & $0.27 * *$ & $0.25 *$ & -0.07 & $-0.25 *$ & 0.19 & $0.28 * *$ & 0.006 & $0.34 * *$ & $0.268 *$ \\
\hline NPB & -0.1887 & & & & & & 1 & $0.41 * *$ & 0.11 & -0.1 & $0.32 * *$ & $0.40 * *$ & $-0.27 * *$ & 0.10 & 0.170 \\
\hline NSB & 0.343 & & & & & & & 1 & $0.35^{* *} *$ & 0.05 & 0.18 & $0.60 * *$ & -0.02 & 0.04 & $0.51 * *$ \\
\hline $\mathbf{P} / \mathbf{P}$ & 0.1762 & & & & & & & & 1 & $0.29 * *$ & -0.08 & $0.45 * *$ & 0.11 & $-0.33 * *$ & $0.51 * *$ \\
\hline $\mathbf{S} / \mathbf{P}$ & 0.1219 & & & & & & & & & 1 & $-0.28 * *$ & -0.02 & 0.17 & $-0.64 * *$ & 0.09 \\
\hline DM & -0.0284 & & & & & & & & & & 1 & 0.14 & -0.12 & $0.22 *$ & 0.05 \\
\hline BY & -1.3635 & & & & & & & & & & & 1 & 0.191 & 0.1628 & $0.76^{* * *}$ \\
\hline HI & -0.467 & & & & & & & & & & & & 1 & 0.034 & $0.46^{* *}$ \\
\hline TW & -0.0726 & & & & & & & & & & & & & 1 & 0.122 \\
\hline SYP & 1.2983 & & & & & & & & & & & & & & 1 \\
\hline
\end{tabular}

$\mathrm{DE}=$ Direct effect; $\mathrm{DF}=$ Days to $50 \%$ flowering; $\mathrm{LSL}=$ Length of leaf let size $(\mathrm{mm}) ; \mathrm{LSW}=\mathrm{Width}$ of leaf let size $(\mathrm{mm}) ; \mathrm{PH}=\mathrm{Plant}$ height $(\mathrm{cm}) ; \mathrm{BH}=\mathrm{Basal}$ height $(\mathrm{cm}) \mathrm{NPB}=$ Number of primary branches per plant; NSB $=$ Number of secondary branches per plant; $\mathrm{P} / \mathrm{P}=\mathrm{Number}$ of pods per plant; $\mathrm{S} / \mathrm{P}=$ number of seeds per pod; DM = Days to maturity; BY = Biological yield per plant $(\mathrm{g}) ; \mathrm{HI}=$ Harvest index $(\%) ; \mathrm{TW}=\mathrm{Test}$ weight $(\mathrm{g}) ; \mathrm{SYP}=\mathrm{seed}$ yield per plant $(\mathrm{g})$ $\mathrm{r}=0.2687=0.01 \%(* *)$

$0.2061=0.05 \%(*)$ 
Table.2 Direct and indirect effects of green chickpea genotypes for quantitative traits at phenotypic level

\begin{tabular}{|c|c|c|c|c|c|c|c|c|c|c|c|c|c|c|c|}
\hline Traits & DF & LLS & WLL & PH & $\mathbf{B H}$ & NPB & NSB & $\mathbf{P} / \mathbf{P}$ & $\mathbf{S} / \mathbf{P}$ & DM & BY & HI (\%) & TW & DE & $\mathbf{r ( S Y P )}$ \\
\hline DF & & -0.0139 & -0.007 & -0.0077 & -0.0221 & -0.0234 & -0.0077 & 0.0032 & 0.0153 & -0.0223 & -0.0095 & 0.0181 & -0.0103 & -0.0535 & -0.0566 \\
\hline LSL & 0.0857 & & 0.2821 & 0.1136 & 0.1388 & 0.0502 & 0.0037 & -0.0217 & -0.1338 & 0.0049 & 0.0905 & -0.0018 & 0.1638 & 0.329 & $-0.247 *$ \\
\hline LSW & -0.0259 & -0.1709 & & -0.0685 & -0.0705 & -0.0288 & -0.0193 & 0.0244 & 0.0824 & 0.0002 & -0.06 & 0.0095 & -0.1112 & -0.1994 & $0.232 *$ \\
\hline$\overline{\mathbf{P H}}$ & 0.0278 & 0.0665 & 0.0662 & & 0.1659 & 0.0313 & 0.0676 & 0.0043 & -0.028 & 0.087 & 0.0747 & 0.0183 & 0.0658 & 0.1927 & $0.407 * *$ \\
\hline $\mathbf{B H}$ & 0.0736 & 0.0751 & 0.063 & 0.1533 & & 0.0481 & 0.0446 & -0.0126 & -0.0454 & 0.0347 & 0.05 & 0.0012 & 0.0612 & 0.1781 & $0.268 *$ \\
\hline NPB & -0.0826 & -0.0288 & -0.0273 & -0.0306 & -0.051 & & -0.0791 & -0.0208 & 0.0196 & -0.0612 & -0.0761 & 0.0512 & -0.0202 & -0.1887 & 0.173 \\
\hline NSB & 0.049 & 0.0038 & 0.0332 & 0.1204 & 0.0858 & 0.1439 & & 0.1233 & 0.0175 & 0.064 & 0.2069 & -0.0089 & 0.014 & 0.343 & $0.515 *$ \\
\hline $\mathbf{P} / \mathbf{P}$ & -0.0106 & -0.0116 & -0.0216 & 0.0039 & -0.0124 & 0.0194 & 0.0633 & & 0.0515 & -0.0142 & 0.0809 & 0.02 & -0.0586 & 0.1762 & $0.511 *$ \\
\hline $\mathbf{S} / \mathbf{P}$ & -0.0348 & -0.0496 & -0.0504 & -0.0177 & -0.0311 & -0.0127 & 0.062 & 0.0356 & & -0.0348 & 0.0026 & 0.0219 & -0.0789 & 0.1219 & 0.096 \\
\hline$\overline{\text { DM }}$ & -0.0118 & 0.0004 & 0.0001 & -0.0013 & -0.0055 & -0.091 & -0.0053 & 0.0023 & 0.081 & & 0.0041 & 0.0036 & -0.0062 & -0.0284 & 0.055 \\
\hline$\overline{\text { BY }}$ & -0.2413 & -0.375 & -0.4103 & -0.5286 & -0.3829 & -0.5495 & -0.8223 & -0.6265 & 0.0295 & -0.1972 & & 0.2613 & -0.222 & -1.3635 & $0.767 * *$ \\
\hline HI & 0.1576 & 0.0026 & 0.0223 & -0.0444 & 0.0031 & 0.1268 & 0.0122 & -0.0529 & -0.084 & 0.0597 & 0.0895 & & 0.0159 & -0.467 & $0.466 * *$ \\
\hline TW & -0.014 & -0.0361 & -0.0405 & -0.0248 & -0.0249 & -0.0078 & -0.003 & 0.0242 & 0.047 & -0.016 & -0.0118 & 0.0025 & & -0.0726 & 0.122 \\
\hline
\end{tabular}

$\mathrm{DF}=$ Days to 50\% flowering; LSL = Length of leaf let size $(\mathrm{mm}) ; \mathrm{LSW}=$ Width of leaf let size $(\mathrm{mm}) ; \mathrm{PH}=\mathrm{Plant}$ height $(\mathrm{cm}) ; \mathrm{BH}=\mathrm{Basal}$ height $(\mathrm{cm}) ; \mathrm{NPB}=$ Number of primary branches per plant; NSB = Number of secondary branches per plant; $\mathrm{P} / \mathrm{P}=\mathrm{Number}$ of pods per plant; $\mathrm{S} / \mathrm{P}=$ number of seeds per pod; DM = Days to maturity; BY = Biological yield per plant $(\mathrm{g}) ; \mathrm{HI}=$ Harvest index $(\%)$; $\mathrm{TW}=$ Test weight $(\mathrm{g})$; DE= Direct effect $; \mathrm{SYP}=\mathrm{seed}$ yield per plot $(\mathrm{g})$; $\mathrm{r}=$ correlation

$* *=>$ Significant at $\mathrm{P}=0.01$

Phenotypic residual value $=0.6135$ 


\section{Direct effects on seed yield per plant}

Six out of 14 characters had positive and direct effect on seed yield per plot at phenotypic level. The characters number of secondary branches (0.3430) has highest positive direct effect on seed yield per plant followed by length of leaf let size (0.3290), plant height (0.1927), basal height (0.1781), number of pods per plant (0.1762) and number of seeds per pod (0.1219). Whereas, biological yield (-1.3635) had highest negative direct effect on seeds yield per plant followed by harvest index (-0.4670), width of leaf let size (-0.1994), number of primary branches $(-0.1887)$, test weight $(-0.0726)$, days to 50 per cent flowering (-0.0535) and days to maturity (-0.0284), these findings are supported by earlier findings of Akanksha et al., 2016; Anita et al., 2015; Mishra and Babbar 2014).

\section{Indirect effects on seed yield per plant}

Among the productive traits indirect positive effect on number of pods per plant with number of seeds per pod (0.0515), number of pods per plant with the test $(-0.0586)$ and number of seeds per pod with test weight (0.0789 ) will influence indirectly to increases overall seed yield per plant.

In addition, indirect effect of physiological traits such as days to 50 per cent flowering, days to maturity, biological yield and harvest index will influence indirect and positive effect on seed yield per plant. Among the physiological traits days to 50 per cent flowering with days to maturity (-0.0223), days to 50 per cent flowering with biological yield per plant (-0.0095), days to 50 per cent flowering with harvest index (0.0181), days to maturity with biological yield (0.0041), days to maturity with harvest index (0.0036) and biological yield with harvest index $(0.2613)$ will influence indirect positive effect on increase in overall seed yield per plant. Further indirect effect of agronomical traits such as plant height, basal height, number of primary and secondary branches per plant on seed yield per plant. Among the agronomical traits plant height with basal height (0.1659), plant height with number of primary branches (0.0313), plant height with secondary branches per plant (0.0676), basal height with secondary branches (0.0446), basal height with number of primary branches per plant (0.0481), number of primary branches with number of secondary branches per plant (0.0791) will influence indirect effect for increase in overall seed yield per plant (Bakhsh et al., 2006; Durga et al., 2007; Dhameliya et al., 2008).

\section{Residual effect}

It is difficult enough to have complete knowledge of all component traits of yield, since the performance of the traits in majority of circumstance is influenced by residual effect. The residual effect permits precise explanation about the pattern of interaction of other possible components of yield. In other words, residual effect measures the role of other possible independent variables which were not included in the study on the dependent variables. The residual effect is high and it indicates that besides the characters studied, there are some other attributes which contributes for yield.

Yield being a complex trait influenced directly and indirectly through other component traits. In present investigation seven out of 14 characters are having direct positive effect on seed yield viz., length of leaf let size, plant height, basal height, number of secondary branches per plant, number of pods per plant, number of seeds per pod and negative direct effect was noticed for days to 50 per cent flowering, width of leaf let size, number of secondary branches 
per plant, days to maturity, biological yield, harvest index and test weight, these findings are in accordance with the earlier studies of (Mohammad et al., 1992; and Arshad et al., 2004). The traits study which were effecting yield directly accessible for environment, hence the selection based on these traits would be results in unsucces.

\section{References}

Anita, B., Andey. S. and Singh, R. 2015. Genetic studies on chickpea genotypes grown in late sown under rice fallow conditions of Madhya Pradesh. Electronic Journal of Plant Breeding, 6(3): 738-748.

Anita, B., Prakash, V., Tiwari, P. and Iquebal, M., 2012. Genetic variability for chickpea (cicer arietinum) under late sown season. Division of Biometrics \& Statistical Modelling, IASR Institute, New Delhi-India. Legume Res., 35(1).

Arshad, M., Bakhsh, A. and Ghafoor, A., 2004. Path coefficient analysis in chickpea (Cicer arietinum L.) under rainfed conditions. Pak. J. Bot., 36(1): 75-81.

Babbar, A. and Patel, S. K., 2005. Correlation and path analysis in Desi chickpea under Kymore plateau Zone of Madhya Pradesh. J.N.K.V.V. Res. J., 39 (1): 4751.

Bakhsh, A., Arshad, M. and Haqqani, A. M.
2006. Effect of genotype $\times$ environment interaction on relationship between grain yield and its components in chickpea [Cicer arietinum (L.)]. Pak. J. Bot. 38(3): 683- 690.

Dhameliya, H. R., Ramani, V. V. and Pithia, M. S., 2008. Variability and correlation studies for seed yield and its components in Desi chickpea. Inter. J. Pl. Sci. 3(2): 369-371.

Durga, K. K., Murthy, S. S. N., Rao, Y. K. and Reddy, M. V., 2007. Genetic studies on yield and yield components of chickpea. Agri. Sci. Digest., 27(3): 201- 203.

Mishra, S. and Babbar, A., 2014. Selection strategies to assess the promising Kabuli chickpea promising lines under normal and heat stress environments. Electron. J. Pl. Breed., 5(2): 260-267.

Mohammad, A., Khan, N. A., Mirza, M. S. and Rehman Khan, A., 1992. Correlation and Path coefficient analysis for yield components in soybean. Pakistan J. Agric. Res, P.13.

Sanjeev, K. S., 2016. Association studies for seed yield and its attributing traits in Desi chickpea (cicer arietinum L.) varieties. Legume Genomics and Genetics, 7(3): 1-6.

Singh, R. K. and Chaudhary, B. D., 1979. Biometrical methods in quantitative genetic analysis. Kalyani Pub. New Delhi, India.

\section{How to cite this article:}

Honnappa, D.M. Mannur and Muniswamy, S. 2018. Association and Path Coefficient Analysis of Various Component Traits with Seed Yield Per Plant for Quantitative Traits in Advance Generation (F5) of Cross Between Green Seeded Desi (GKB-10) and White Kabuli (MNK-1) Chickpea Genotypes (Cicer arietinum L.). Int.J.Curr.Microbiol.App.Sci. 7(01): 459-465. doi: https://doi.org/10.20546/ijcmas.2018.701.054 